\title{
Liver cancer stem cells are selectively enriched by low-dose cisplatin
}

\author{
H. Zhang, W.J. Chang, X.Y. Li, N. Zhang, J.J. Kong and Y.F. Wang \\ Department of Internal Medicine, First Affiliated Hospital, Dalian Medical University, Dalian, China
}

\begin{abstract}
Accumulating evidence has indicated the importance of cancer stem cells in carcinogenesis. The goal of the present study was to determine the effect of low-dose cisplatin on enriched liver cancer stem cells (LCSCs). Human hepatoblastoma HepG2 cells were treated with concentrations of cisplatin ranging from 1 to $5 \mu \mathrm{g} / \mathrm{mL}$. Cell survival and proliferation were evaluated using a tetrazolium dye (MTT) assay. LCSCs were identified using specific markers, namely aldehyde dehydrogenase-1 (ALDH1) and CD133. The percentage of ALDH1 + or CD133 + cells was examined by flow cytometric analysis. The expression of ALDH1 and/or CD133 in HepG2 cells was determined by immunocytochemical analysis. Low-dose cisplatin treatment significantly decreased cell survival in HepG2 cells after 24 or $72 \mathrm{~h}$. However, the percentage of LCSCs in the surviving cells was greatly increased. The percentage of ALDH1 + or CD133 + cells was increased in a time- and dose-dependent manner after treatment with 1-4 $\mu \mathrm{g} / \mathrm{mL}$ cisplatin, whereas $5 \mu \mathrm{g} / \mathrm{mL}$ cisplatin exposure slightly reduced the number of positive cells. These findings indicate that low-dose cisplatin treatment may efficiently enrich the LCSC population in HepG2 cells.
\end{abstract}

Key words: Cisplatin; Liver cancer stem cell; HepG2; ALDH1; CD133

\section{Introduction}

Hepatocellular carcinoma (HCC) is one of the most common cancers worldwide and the leading cause of cancer mortality (1). Although understanding of the molecular mechanisms involved in the initiation and progression of $\mathrm{HCC}$ has been increasing, data on the impact of cancer stem cells on hepatocarcinogenesis are inconsistent (2).

It has been suggested that cancer is unicellular in origin, and only a small population of cancer cells have the ability to self-renew and thus drive the growth and spread of a tumor (3). HCC is thought to be comprised of morphologically diverse cell types that express a variety of hepatic lineage markers. Chiba et al. (4) reported that subpopulations of cancer stem cells exist in some HCC cell lines, including the human liver cancer cell lines, Huh7 and PLC/PRF/5. Cancer stem cells are also closely associated with the recurrence and metastasis of tumors $(5,6)$. The identification and characterization of liver cancer stem cells (LCSCs) in HCC cells may help to develop effective and targeted therapies.

CD133 is a molecular marker that can be used to characterize HCC cells as cancer stem cells or progenitor cells (7). Expression of CD133 has been detected in various human liver cancer cell lines, including the $\mathrm{HCC}$, SMMC-7721, Huh7 and Hep3B, the metastatic HCC cell lines MHCC-LM3 and MHCC-97L, and the hepatoblastoma cell line HepG2 (8). Aldehyde dehydrogenase-1 (ALDH1) is another cancer stem cell marker that can be used to discriminate CD133 + LCSC populations (9). ALDH1 expression, in combination with CD133 expression, more specifically characterizes the tumorigenic LCSC population (10).

Chemotherapy may induce genomic instability in the cells of a tumor mass and eventually enrich LCSCs (11). The present study used low-dose cisplatin, a common chemotherapeutic agent, to enrich LCSCs in HepG2 cells, offering a novel approach to study the tumorigenesis of HCC.

\section{Material and Methods}

\section{Reagents}

Cisplatin was purchased from Jiangsu Hansoh Pharmaceutical Co., Ltd. (China). Dulbecco's modified Eagle's medium (DMEM) was purchased from Gibco BRL (USA). Fetal bovine serum (FBS) was provided by Zhejiang Tianhang Biological Technology Co., Ltd. (China) and propidium iodide (PI) was purchased from Sigma (USA). Fluorescein isothiocyanate (FITC)-conjugated mouse

Correspondence: Hua Zhang, Department of Internal Medicine, First Affiliated Hospital, Dalian Medical University, 222 Zhongshan Road, Xigang District, Dalian 116011, Liaoning Province, China. Fax: +86-411-8439-4739. E-mail: zhanghua2233@126.com 
anti-human anti-ALDH1 monoclonal antibody, phycoerythrin (PE)-conjugated mouse anti-human anti-CD133 monoclonal antibody, as well as the isotype control, were obtained from eBioscience (USA).

\section{Cell culture}

Human hepatoblastoma HepG2 cells were provided by the First Affiliated Hospital of Dalian Medical University. Cells were maintained in DMEM supplemented with $10 \%$ FBS in a humidified, $5 \% \mathrm{CO}_{2}$ incubator at $37^{\circ} \mathrm{C}$.

\section{Cell proliferation}

Cell proliferation was measured using the 3-(4,5dimethylthiazol-2-yl)-2,5-diphenyltetrazolium bromide (MTT) assay based on reduction of the tetrazolium dye. HepG2 cells were seeded onto 96-well plates at a density of $1 \times 10^{4}$ cells/well prior to drug treatment. Confluent cultures were treated with $1,2,3,4$, and $5 \mu \mathrm{g} / \mathrm{mL}$ cisplatin. Cells without drug exposure were used as control. At different times after drug treatment, $10 \mu \mathrm{L}$ MTT $(5 \mathrm{mg} / \mathrm{mL})$ was added to each well. After an additional 4-h incubation at $37^{\circ} \mathrm{C}$, the medium was removed and $150 \mu \mathrm{L}$ dimethyl sulfoxide was added to each well to resuspend the MTT metabolic product. The absorbance of the dissolved formazan was measured at $490 \mathrm{~nm}\left(\mathrm{~A}_{490}\right)$ using a scanning microplate spectrophotometer (Shanghai Touching Technology Co., Ltd., China). Cell survival rate is reported as percent.

\section{Flow cytometric analysis}

HepG2 cells in the log phase were collected and seeded onto 6 -well plates at a density of $4 \times 10^{5}$ cells/well. Twenty-four hours later, cells were treated with 1, 2, 3, 4, and $5 \mu \mathrm{g} / \mathrm{mL}$ cisplatin. After 24, 48, and $72 \mathrm{~h}$, cells were collected and adjusted to a density of $1 \times 10^{6}$ cells $/ \mathrm{mL}$. Cell samples were stained with anti-ALDH1-FITC antibody (1:1000), anti-CD133-PE antibody (1:1000), or an isotype control (1:1000) for $30 \mathrm{~min}$ at room temperature. The percentages of ALDH1 + or CD133 + cells were analyzed using fluorescent-activated cell sorting (FACS) equipment (Beckman Coulter, USA).

\section{Immunocytochemistry}

For immunostaining, cells were cultured on 6 -well plates and treated with $1,2,3,4$, or $5 \mu \mathrm{g} / \mathrm{mL}$ cisplatin for $48 \mathrm{~h}$. Cells were washed twice gently with phosphate-buffered saline and fixed in 4\% paraformaldehyde overnight. Subsequently, samples were incubated with anti-ALDH1FITC and/or anti-CD133-PE antibodies for $1 \mathrm{~h}$ at $37^{\circ} \mathrm{C}$. After washing with PBS, samples were incubated with $\mathrm{PI}$ (1:2000) for another $15 \mathrm{~min}$. Images were captured using a fluorescence microscope (DMI 4000B Leica, Germany).

\section{Statistical analysis}

Data were analyzed using the SPSS software, version 16.0 (IBM Corporation, USA). Data are reported as

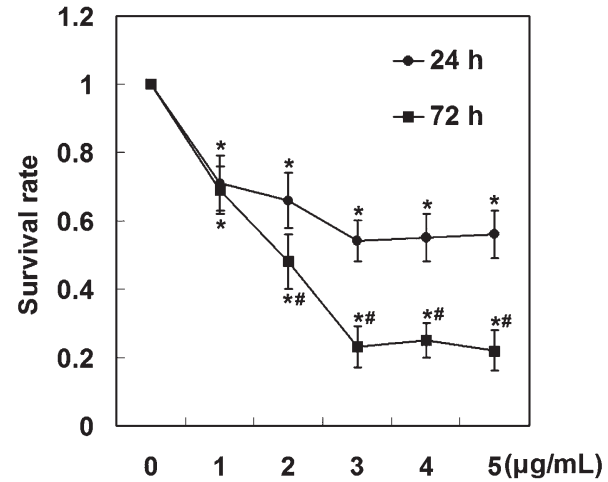

Figure 1. Cell survival following low-dose cisplatin treatment HepG2 cells were treated with $0-5 \mu \mathrm{g} / \mathrm{mL}$ cisplatin, and cell survival was determined by the MTT assay after 24 or $72 \mathrm{~h}$. Data were calculated from two independent experiments. ${ }^{*} \mathrm{P}<0.05$ compared with $0 \mu \mathrm{g} / \mathrm{mL}$ cisplatin treatment; ${ }^{\#} \mathrm{P}<0.05$ compared with $24 \mathrm{~h}\left(\chi^{2}\right.$ test).

means \pm SD. Comparisons between two groups were carried out using the $\chi^{2}$ test or multifactor ANOVA. $\mathrm{P}<0.05$ was considered to be significantly different.

\section{Results}

\section{Cell survival}

Survival of human hepatoblastoma HepG2 cells was assessed following treatment with varied concentrations of cisplatin. As shown in Figure 1, treatment with low cisplatin doses $(1-5 \mu \mathrm{g} / \mathrm{mL})$ decreased the cell survival rate after 24 or $72 \mathrm{~h}$ of drug incubation $(\mathrm{P}<0.05$ compared with controls). Compared to $24 \mathrm{~h}$, prolonged cisplatin exposure (72 h) significantly enhanced cell death $(\mathrm{P}<0.05)$. These data indicate that cisplatin treatment reduced survival of HepG2 cells.

\section{Flow cytometry}

In order to evaluate the percentage of cancer stem cells in the total HepG2 cell population following exposure to low-dose cisplatin, cells were labeled with the cancer stem cell markers ALDH1 $(9,10)$ and $\operatorname{CD} 133(7,12)$. Flow cytometric analysis showed that the percentages of ALDH1 + and CD133 + cells increased in a time- and dose-dependent manner after 24 or $72 \mathrm{~h}$ of $1-4 \mu \mathrm{g} / \mathrm{mL}$ cisplatin treatment (Figure 2). However, treatment with $5 \mu \mathrm{g} / \mathrm{mL}$ cisplatin slightly decreased the number of $\mathrm{ALDH} 1+$ and CD133 + cells. These results suggest that low-dose cisplatin treatment promoted the generation of cancer stem cells.

\section{Immunocytochemistry}

HepG2 cells treated for $48 \mathrm{~h}$ with $4 \mu \mathrm{g} / \mathrm{mL}$ cisplatin, the dose that induced the most efficient enrichment of LCSCs, were examined for expression of both ALDH1 and CD133 markers. As shown in Figure 3, ALDH1 and 

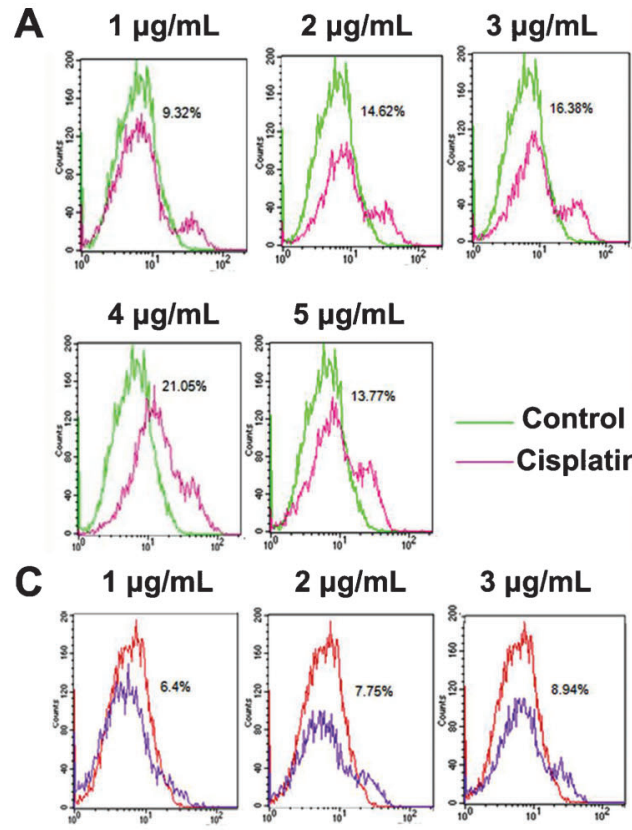

$4 \mu \mathrm{g} / \mathrm{mL} \quad 5 \mu \mathrm{g} / \mathrm{mL}$

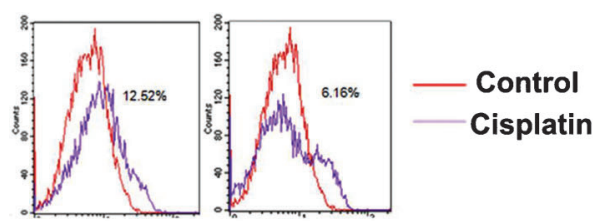

B

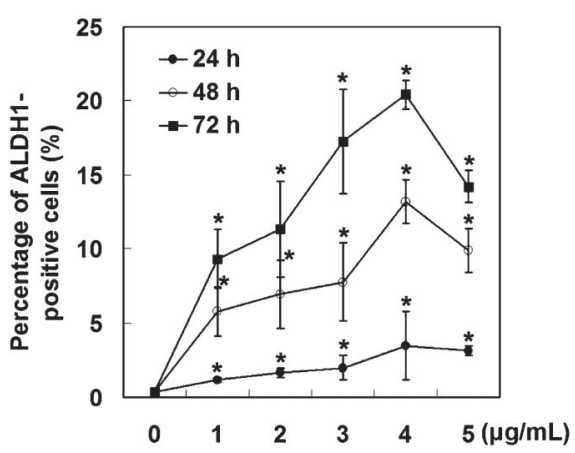

D

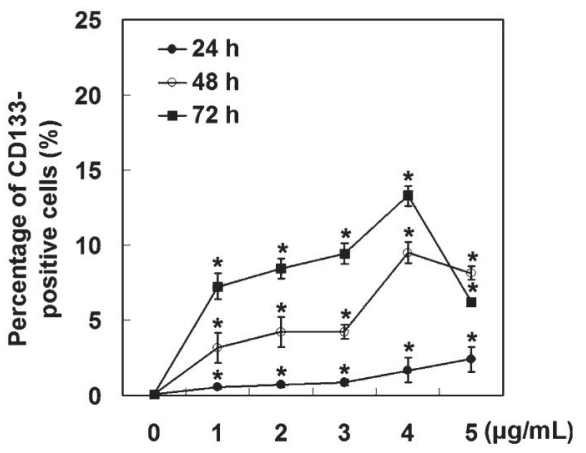

Figure 2. Flow cytometric analysis of the number of ALDH1 + and CD133+ cells. HepG2 cells were treated with 0-5 $\mu \mathrm{g} / \mathrm{mL}$ cisplatin. The percentage of $\operatorname{ALDH} 1+(A, B)$ or $\mathrm{CD} 133+(C, D)$ cells at 24,48 , or $72 \mathrm{~h}$ following drug treatment was assessed by flow cytometric analysis. Data were calculated from three independent experiments. ${ }^{*} \mathrm{P}<0.05$ compared with $0 \mu \mathrm{g} / \mathrm{mL}$ cisplatin treatment $\left(\chi^{2}\right.$ test). Representative flow cytometry data are presented in Panels $A$ and $C$.

CD133 were diffusely distributed in the cytoplasm and plasma membranes of control HepG2 cells. Conversely, treatment with $4 \mu \mathrm{g} / \mathrm{mL}$ cisplatin strongly increased the intensity of fluorescence in ALDH1 + and/or CD133 + cells following a 48-h drug exposure. Moreover, the positive staining showed a cobblestone appearance in both cases. Thus, immunocytochemical analysis also demonstrated that cisplatin treatment increased the proportion of cancer stem cells.

\section{Discussion}

One theory proposes that cancers arise from cancer stem cells or cancer progenitor cells that make up a small proportion of the cells within tumors (3). Recent studies have shown that cancer stem cells are closely correlated with the outcome of chemotherapy because of their role in chemoresistance. Lee et al. (6) showed that putative cancer stem cells in breast tumors were chemoresistant and associated with tumor progression. It was suggested that tumor recurrence might result from the resistance of residual cancer stem cells following chemotherapy (13). Furthermore, a more recent prospective study showed that patients with recurrence had higher median levels of circulating cancer stem cells, thus circulating HCC stem cells might predict recurrence after hepatectomy (5).

It has also been suggested that tumor stem cells may influence chemotherapy resistance by inducing targetrelated protein mutations, opposing anti-apoptotic processes, and enhancing drug efflux (14). Ma et al. (15) showed that activation of the Akt/PKB survival pathway in CD133 + HCC cancer stem cells conferred resistance to chemotherapeutic agents. Hence, enrichment of cancer stem cells by chemotherapeutic drugs may provide a novel and convenient way to understand the characteristics of cancer stem cells.

In a preliminary study investigating the cytotoxic effects of cisplatin in vitro, we determined that the $\mathrm{IC}_{50}$ value was $3.4 \mu \mathrm{g} / \mathrm{mL}$ after cells were exposed to cisplatin for $48 \mathrm{~h}$ (data not shown). Doses of cisplatin greater than $10 \mu \mathrm{g} / \mathrm{mL}$ resulted in $80 \%$ cell death, thus a dose of 1 $5 \mu \mathrm{g} / \mathrm{mL}$ was selected for the present study. The results 


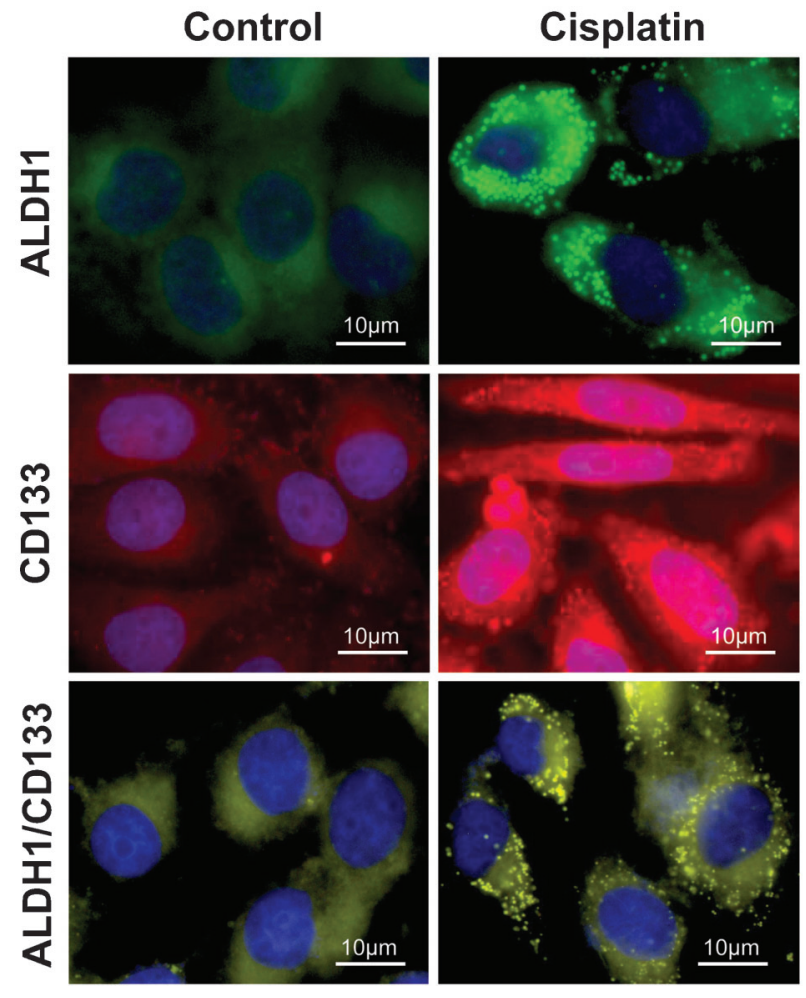

Figure 3. Immunocytochemical analysis of ALDH1+ and CD133 + cells. HepG2 cells were treated with $4 \mu \mathrm{g} / \mathrm{mL}$ cisplatin. Forty-eight hours after drug treatment, cells were stained with anti-ALDH1-FITC (upper panels) or anti-CD133-PE (middle panels). Bottom panels are merged data. Nuclei were labeled with propidium iodide (blue).

showed that low doses of cisplatin (1-5 $\mu \mathrm{g} / \mathrm{mL})$ significantly decreased HepG2 cell survival rate after 24 or $72 \mathrm{~h}$ and increased tumor cell suppression after $72 \mathrm{~h}$ compared with a 24-h incubation. Although the majority of hepatoma cells died following cisplatin therapy, a small population of cells survived. Immunocytochemical analysis and flow cytometric analysis confirmed that most of the surviving cells expressed ALDH1 and CD133 proteins, which are cancer stem cell biomarkers. Furthermore, $72 \mathrm{~h}$ of treatment with $4 \mu \mathrm{g} / \mathrm{mL}$ cisplatin provided the greatest enrichment of LCSCs in the HepG2 cell line. However, cisplatin dosages above $4 \mu \mathrm{g} / \mathrm{mL}$ slightly reduced the percentage of ALDH1+ and CD133+ cells, perhaps because of cell death from the increased concentration of the drug. These findings indicate that low doses of cisplatin (1-4 $\mu \mathrm{g} / \mathrm{mL}$ ) may inhibit the growth of HepG2 cells, but enhance the percentage of LCSCs in surviving cells. Therefore, low-dose cisplatin may be used to induce the enrichment of LCSCs in a given cell population.

It is possible that, following chemotherapy, recurrent tumors show enhanced malignancy due to an increased percentage of cancer stem cells. Indeed, Dylla et al. (16) reported that human colorectal cancer stem cells were enriched in colon tumors following chemotherapy and remained capable of rapidly regenerating the tumors from which they originated. Similar results were observed following chemotherapy of thyroid carcinoma (17). One possibility is that cancer stem cells remain at rest in the G0 phase of the cell cycle, and are thus not sensitive to chemotherapy because most drugs selectively kill proliferating cells (18). Conversely, the genomic instability of tumor cells may contribute to the new generation of cancer stem cells, and this process may be potentiated by exposure to chemotherapeutic agents (19). Cancer stem cells exhibit several characteristics, such as an active DNA repair system and expression of anti-apoptotic factors, which may promote chemotherapeutic resistance. Consequently, complete disease remission might only be obtained after total elimination of the cancer stem cell population (19).

Identifying the role that LCSCs play in tumorigenesis will provide new approaches for the treatment of liver cancer, such as the targeting of specific molecular pathways. For example, EpCAM-specific antibodies can efficiently reduce the number of EpCAM + LCSCs (20), and antibodies targeting CD133/CD44 can be used to suppress the growth of CD133+/CD44+ LCSCs (8). By enriching the LCSC population and identifying the surface markers for these stem cells, our current study provides a valuable technique for targeted therapy of liver tumors.

In summary, the present study established a novel strategy to enrich ALDH1 + and CD133 + LCSCs from HepG2 cells in vitro using low doses of cisplatin. LCSCs may contribute to the resistance of HCCs to chemotherapy and promote cancer progression and recurrence. These findings provide a simple and effective method for enriching the stem cell population in an established HCC cell line.

\section{Acknowledgments}

Research supported by the Science and Technology Project of Liaoning Province (\#2011225013) and the Science and Technology Project of Dalian City (\#2010E15SF178).

\section{References}

1. El-Serag HB, Rudolph KL. Hepatocellular carcinoma: epidemiology and molecular carcinogenesis. Gastroenterology 2007; 132: 2557-2576, doi: 10.1053/j.gastro.2007.04.061.

2. Villanueva A, Newell P, Chiang DY, Friedman SL, Llovet JM.

Genomics and signaling pathways in hepatocellular carcinoma. Semin Liver Dis 2007; 27: 55-76, doi: 10.1055/s-2006960171.

3. Clarke MF, Fuller M. Stem cells and cancer: two faces of 
eve. Cell 2006; 124: 1111-1115, doi: 10.1016/j.cell.2006.03. 011.

4. Chiba T, Kita K, Zheng YW, Yokosuka O, Saisho H, Iwama $A$, et al. Side population purified from hepatocellular carcinoma cells harbors cancer stem cell-like properties. Hepatology 2006; 44: 240-251, doi: 10.1002/hep.21227.

5. Fan ST, Yang ZF, Ho DW, Ng MN, Yu WC, Wong J. Prediction of posthepatectomy recurrence of hepatocellular carcinoma by circulating cancer stem cells: a prospective study. Ann Surg 2011; 254: 569-576, doi: 10.1097/ SLA.0b013e3182300a1d.

6. Lee HE, Kim JH, Kim YJ, Choi SY, Kim SW, Kang E, et al. An increase in cancer stem cell population after primary systemic therapy is a poor prognostic factor in breast cancer. Br J Cancer 2011; 104: 1730-1738, doi: 10.1038/ bjc.2011.159.

7. Suetsugu A, Nagaki M, Aoki $H$, Motohashi $T$, Kunisada $T$, Moriwaki $\mathrm{H}$. Characterization of $\mathrm{CD} 133+$ hepatocellular carcinoma cells as cancer stem/progenitor cells. Biochem Biophys Res Commun 2006; 351: 820-824, doi: 10.1016/ j.bbrc.2006.10.128.

8. Zhu Z, Hao X, Yan M, Yao M, Ge C, Gu J, et al. Cancer stem/ progenitor cells are highly enriched in CD133+CD44+ population in hepatocellular carcinoma. Int J Cancer 2010; 126: 2067-2078, doi: 10.1002/ijc.24728.

9. Douville J, Beaulieu R, Balicki D. ALDH1 as a functional marker of cancer stem and progenitor cells. Stem Cells Dev 2009; 18: 17-25, doi: 10.1089/scd.2008.0055.

10. Ma S, Chan KW, Lee TK, Tang KH, Wo JY, Zheng BJ, et al. Aldehyde dehydrogenase discriminates the CD133 liver cancer stem cell populations. Mol Cancer Res 2008; 6: 1146-1153, doi: 10.1158/1541-7786.MCR-08-0035.

11. Liang $Y$, Zhong Z, Huang Y, Deng W, Cao J, Tsao G, et al. Stem-like cancer cells are inducible by increasing genomic instability in cancer cells. J Biol Chem 2010; 285: 49314940, doi: 10.1074/jbc.M109.048397.

12. Wu Y, Wu PY. CD133 as a marker for cancer stem cells: progresses and concerns. Stem Cells Dev 2009; 18: 1127 1134, doi: 10.1089/scd.2008.0338.

13. Dean M, Fojo $T$, Bates $S$. Tumour stem cells and drug resistance. Nat Rev Cancer 2005; 5: 275-284, doi: 10.1038/ nrc1590.

14. Moitra K, Lou H, Dean M. Multidrug efflux pumps and cancer stem cells: insights into multidrug resistance and therapeutic development. Clin Pharmacol Ther 2011; 89: 491-502, doi: 10.1038/clpt.2011.14.

15. Ma S, Lee TK, Zheng BJ, Chan KW, Guan XY. CD133+ $\mathrm{HCC}$ cancer stem cells confer chemoresistance by preferential expression of the Akt/PKB survival pathway. Oncogene 2008; 27: 1749-1758, doi: 10.1038/sj.onc.1210811.

16. Dylla SJ, Beviglia L, Park IK, Chartier C, Raval J, Ngan L, et al. Colorectal cancer stem cells are enriched in xenogeneic tumors following chemotherapy. PLoS One 2008; 3: e2428, doi: 10.1371/journal.pone.0002428.

17. Zheng X, Cui D, Xu S, Brabant G, Derwahl M. Doxorubicin fails to eradicate cancer stem cells derived from anaplastic thyroid carcinoma cells: characterization of resistant cells. Int J Oncol 2010; 37: 307-315, doi: 10.3892/ijo_00000746.

18. Prud'homme GJ. Cancer stem cells and novel targets for antitumor strategies. Curr Pharm Des 2012; 18: 2838-2849, doi: $10.2174 / 138161212800626120$.

19. Bhattacharyya S, Khanduja KL. New hope in the horizon: cancer stem cells. Acta Biochim Biophys Sin 2010; 42: $237-$ 242, doi: 10.1093/abbs/gmq013.

20. Kurtz JE, Dufour P. Adecatumumab: an anti-EpCAM monoclonal antibody, from the bench to the bedside. Expert Opin Biol Ther 2010; 10: 951-958, doi: 10.1517| 14712598.2010.482098. 